\title{
Mobility disincentive
}

Scientists who move between countries or research groups as postdocs take up to nine months longer to achieve tenure at Spanish universities than those who stay put, finds a study (L. Sanz-Menéndez et al. PLoS ONE 8, e77028; 2013). The

MoodRhythm, a smartphone app that tracks sleep patterns and social routines to improve the mental health of people with bipolar disorder, in June won the US\$100,000 Heritage Open $m$ Health Challenge for apps that help patients and clinicians to manage chronic disease. Its developer, Mark Matthews, is an information scientist at Cornell University in Ithaca, New York.

How did you end up working on technology to promote mental health?

After I got my English degree at Trinity College Dublin, I taught English in Paris for a year. I saw that it would soon be possible to develop web-based applications that could combine my interest in games and computers with more practical applications. So I went to Dublin City University and did a master of science in multimedia technology and communications. I worked on 'Savant', which used video, audio and three-dimensional (3D) graphics to depict what it is like to have autism. My team won a Europrix Multimedia Award in 2003. That was my first foray into mental health.

\section{How did that lead to your PhD?}

I realized that mental-health issues have an incredible stigma, which can make people reluctant to seek help. Technology offers a way for people to maintain privacy, dignity and control over their treatment. What sold me on doing a PhD on human-computer interaction was funding from Ireland's Higher Education Authority and the Vodafone Foundation in Newbury, UK. I developed a computer game to engage teenagers in treatment. Teenagers are often not comfortable talking to strangers. My group and I built a 3D game that allows the teen and therapist to maintain a conversation about personal issues without the need for direct eye-to-eye contact - which was a huge factor in its success. The teenager uses an avatar throughout the therapydriven game as the therapist looks on.

How do you determine what clinicians need? It is my job to learn what it is like to be in therapy, to have depression. We involve psychotherapists in our development meetings and I role-play as the patient. I need that to help me understand how to create cutting-edge technologies that will be useful in the clinic.

Was it difficult to secure a research position? In January 2012 I was at a crossroads. I had applied for a lectureship at University College Dublin, and a Marie Curie Fellowship

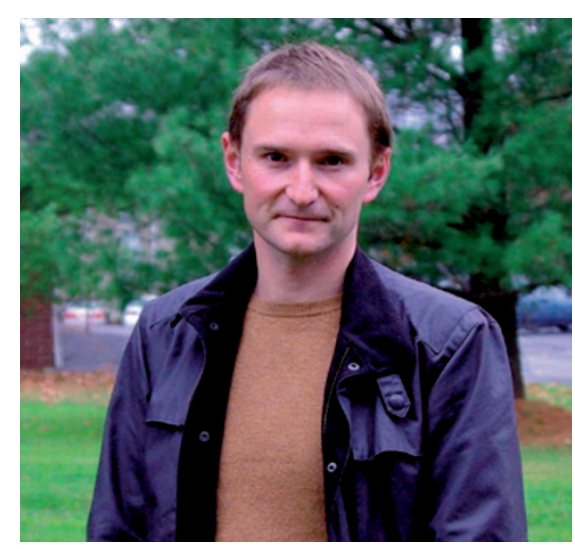

at Cornell. I got both in the space of a week. I had to decide between a five-year position in Dublin, where my family is based but the country is experiencing a deep recession, and the opportunity to work in the United States, which proved too good to turn down. Unfortunately that means that I am separated from my partner and young children for long stretches of time.

\section{How did you secure space at Cornell?}

The year before I applied for the fellowship, I contacted Geri Gay, the head of the interaction-design lab, who was working on ways to record mood. We Skyped a few times to discuss our mutual interests. Once I got the fellowship, I came to Cornell. It has worked out incredibly well. We are developing ways to use smartphones to detect vocal stress or sleep patterns. One of the great things about coming to the United States is getting to work with people at the top of this field.

\section{How might you build a lab when you return to Dublin?}

I know I am not going to walk back into a job, but, in my dream world, I will have a research lab and a commercial venture. I have started thinking about how to get the money together to create a lab. Now that MoodRhythm has won the Open mHealth Challenge, I am looking into how to commercialize the software and use the money to branch out. I am also exploring charities and spending time setting up long-term collaborations between researchers at Trinity College, Cornell and the University of Pittsburgh in Pennsylvania. I have no illusions that it will not be difficult, but I will find a way to do high-impact, top-quality research. authors surveyed about 1,260 academic scientists and engineers who had earned tenure between 1997 and 2001 at public universities in Spain. Corresponding author Luis Sanz-Menéndez, director of the National Research Council Institute of Public Goods and Policies in Madrid, says that to earn tenure in fewer than five years, the study's average, early-career researchers in Spain should remain at their PhD-granting universities. "There are disincentives for people who are highly mobile," he says, although he notes that moves explicitly directed by a mentor had no negative effects.

\section{GRANTS}

\section{Inaccurate predictions}

Peer reviewers for biology grant proposals submitted to the US National Science Foundation (NSF) do not accurately predict the apparent success of projects, according to a study (S. M. Scheiner and L. M. Bouchie Front. Ecol. Environ. 11, 406-407; 2013). Reviewers' scores and rankings for 41 environmental-biology projects funded by the NSF in 2002 did not correlate well with productivity measures, including the number of publications produced by 2012 and the mean number of citations per year. But reviewers do provide value by weeding out flawed proposals and suggesting improvements, says co-author Samuel Scheiner, programme director for the environmental-biology division of the NSF in Arlington, Virginia.

\section{STUDENTS}

\section{Real-time online advice}

A platform launched in October offers free real-time personalized counselling to people who want to study in Europe. Users of EduCoach (www.phdportal.eu) can chat to advisers about 2,500 $\mathrm{PhD}$ programmes at 950 universities across 40 countries. Topics include programme choice, visas, applications, living arrangements, and language and cultural challenges. EduCoach will launch video chats next year, says Sissy Böttcher, project manager with the platform's European Commissionfunded developer, StudyPortals in Eindhoven, the Netherlands. 